\title{
Poverty and Countermeasures on Targeted Poverty Alleviation
}

\author{
Xie Zhixiang* \\ Communication School \\ Yunnan University of Finance and Economics \\ Kunming, China \\ xzxkm@163.com
}

\author{
$\mathrm{Ma} \mathrm{Li}$ \\ Communication School \\ Yunnan University of Finance and Economics \\ Kunming, China \\ 773614690@qq.com
}

\begin{abstract}
China has made remarkable achievements on the work of targeted Poverty Alleviation in 2016, but we still face grave challenges. Due to the fact that poverty has special performance on economy and culture, only by taking targeted measures, can the goal on targeted poverty alleviation be achieved.
\end{abstract}

Keywords-targeted poverty alleviation; poverty;

\section{INTRODUCTION}

In recent years, governments at all levels in Yunnan province have strengthened its support for infrastructure construction and social development in poverty-stricken villages and towns. Poverty alleviation has made remarkable achievements(as shown in Fig.1.), but we still face several difficulties and challenges on conducting the work of poverty alleviation.

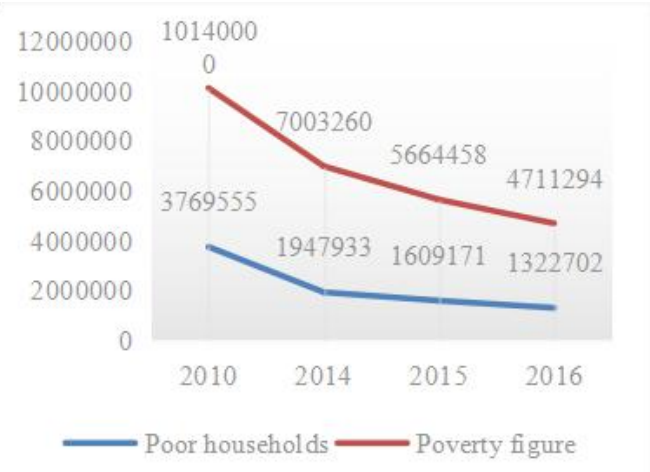

Fig. 1. Poverty alleviation in Yunnan Province in 2011-2016

Source : Yunnan poverty alleviation and Development Office

\section{THE DEFICIENCY OF CONSCIOUSNESS ON POVERTY ALLEVIATION}

With two-to-three years' of government support, many poor households who have been on the administrative record for poverty registering behave passively with the thought of waiting for the well-off society to come, completely relying on government' s support that covering every aspect, but they themselves lack of the determination to cast off poverty. Without initiative and autonomy in work and life, poor households are thus trapping into the vicious circle of 'asking

\footnotetext{
*Corresponding author
}

for more support because of poorer living, getting lazier with more support, and finally results in poorer living.' They are not grateful after receiving related support, but asking for more in return and considered people who help him are merchants.

The limitations of poor households including educational level, family backgrounds explain why they lack of the determination to fight out of poverty, but after all progress still to be made in ideological work, as correct world outlook, values and outlook on life can not be formed naturally, these values can only be instilled into them. As Lenin once pointed out, "it is impossible for workers to have the consciousness of social democracy, which can only be instilled into them."

The ideological work on poor households in povertystricken areas is a long-term process that requires consistent adherence. First of all, more communication is required. In the book "The Essence of Poverty," the author suggests that the poor usually believe in wrong information due to the lack of information sources, and therefore it's necessary to assign people to take responsibility for the work of poverty alleviation, including a team of staff staying at village, keeping a long-term contact with poor households in a manner of care and concern. The responsibility of the participants also includes providing evidences to help poor households to make the correct choice and thus eliminating the sense of insecurity brought by lacking of information. Secondly, to set up an model for poor households. To strengthen ideological education on villagers by making full use of television, film, SMS, WeChat, QQ group, advertisement and other platforms. Besides, opportunities including market day, temple fair, villagers' meeting, weddings, and funerals should be seized to educate villagers with advanced figures and affairs.

\section{TARgeted Poverty Alleviation Is to Be Boosted}

General Secretary $\mathrm{Xi}$ Jinping pointed out that it is of great importance to improve the efficiency on the work of targeted poverty alleviation. It is crucial to find the right way to build a good institutional mechanisms, and to carry out practical work under targeted policy (as shown in Fig. 2.). However, there exist problems on the implementation of targeted measures, for example, the poverty alleviation project in some township governments distributed 3 pigs, 30 chickens, 30 ducks and other livestock to poor households for the sake of increasing their income by rearing these livestock, but many poor households ate or sold these livestock directly for the moment 
of pleasure, they did not take long-term benefits into consideration. This shows that on one hand poor households were inert themselves, which results to poverty, on the other, it suggests that the measures on poverty alleviation formulated by the government was not appropriate and accurate, the outcome management of the project is to be improved.

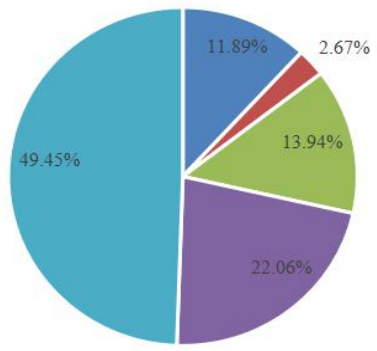

- Social security

- Ecological compensation - Developing education

- Off-site relocatio

- Develop production

Fig. 2. The ratio of five batches

Source : Yunnan poverty alleviation and Development Office

First of all, measures on poverty alleviation is not well targeted. In accordance with the spirit of targeted poverty alleviation, the measure of administrative record for poverty registering should be adopted according to local conditions with attention on differences of each individual. But in our visit to a village committee and households in that village, we found that the residential area is limited with no extra space for pigsty (There's no space for some villagers who're on administrative record for poverty registering to build pigsty because they live next to road), and thus the quality of life declines as human and animal live together; the environment of the village deteriorates as pig run about the village; poor households eat or sell these livestock low income. Moreover, because of limited arable land, some households do not have enough grain, let alone to have more grain to feed pigs or other livestock. In some cases, households do not have extra labor to raise more than one pig, rearing extra livestock brings burden on their shoulders.

Secondly, the outcome management on poverty alleviation is not in place. Although the government of Niujiao village has developed appropriate measures to manage outcomes, but the result is not satisfying because it fails to stimulate poor households' initiative and enthusiasm for work but providing them the gap to be opportunistic. For example, the township government regulates that poor households that are on administrative record for poverty registering will be provided with free livestock including pigs, chickens, and ducks with a deposit of one hundred yuan, the deposit will be returned when the livestock is raised up, but this provision have no restriction on them at all.

Two reasons explain why poverty alleviation is not well targeted, firstly, participants undertaking the project of poverty alleviation are not fulfilling their responsibilities. Moreover, there is a paradox in the policy of targeted poverty alleviation. The policy attaches great importance to individuality and particularity of each poor household, which contradicts the measures implemented on the principle of universality and unity. That means such contradiction makes it difficult to carry out the project in accordance with the principle of "one family, one policy" and "one village one policy", although it is of great value, a challenging task for participants of poverty alleviation to fulfill in reality. Furthermore, with a large population living in poverty, while government of Yunnan province has low fiscal revenue. Given that the complicated geographical environment of Yunnan and limited labor forces, financial resources, such principle has been put on the shelf.

\section{The Problem of Poverty Alleviation on SUSTAINABILITY}

General Secretary Xi said: "poverty alleviation must be well-targeted, and the sustainability of the results on the project should be high valued." As the old saying goes, "give a man a fish, and you have fed him for today; teach a man to fish, and you have fed him for lifetime". In order to achieve sustainable results on poverty alleviation, poor households must be educated from various aspects including vocational education, agricultural technology extension, extension of information channels so as to foster new knowledgetype farmers that have both consciousness and ability of management. In addition, under anti-poverty projects, industries to be developed should be promising. People relocated from inhospitable ares should be better-off, or sustainable efforts must be made on education development. In short, no matter what measures be adopted, we must focus on the long-term sustainability on poverty alleviation, ensuring a sustainable driving force to help poor households to get rid of poverty and become better off.

Through investigation and accounting of revenue and expenditure, we found that the income of households to cast off poverty have reached the standard. Yet before and after making an administrative record for poverty registering, the variety and scale of agricultural products produced by poor households remain almost the same and hence they did not develop any new industries or acquire new skills. Except for poor households with family members as migrant workers, the main reason for their income increase this year is that there are more government subsidies. But once they are no longer on the administrative record for poverty registering, poor households are likely to return to poverty when government subsidies decrease. With no sustainable developing pillar industry and debts ranging from 40 thousand to 100 thousand yuan, their living standard may be poorer than before, leaving the sustainability of poverty alleviation a grave challenge.

There are many reasons why sustainable results cannot be achieved. First of all, fast track approach to poverty alleviation is taken by the local government due to the pressure from performance evaluation, and hence enduring, long-term benefits are hard to be realized. Secondly, personal development of poor households is not concerned while the project emphasizes on relief, subsidize, light industry and training. Thirdly, funds for poor households are integrated and used to cover fees of livelihood projects and image projects. Fourthly, the problem of poverty is not solved fundamentally as support is not extensive and intensive enough, sustainable assistance is not in place, those poor households living in 
extreme remote or poverty-stricken areas are not included in this project.

\section{POVERTy ANALYSIS AND POVERTy ALlEVIATION}

\section{A. "Absolute Poverty" in Economic Context -- Vocational education is suitable for the current rural poverty alleviation}

Absolute poverty, which is also known as living poverty, refers to the fact that individuals and families rely on their labor income and other legal income to maintain their basic survival needs in a given way of social production and life, such individual or family is called the poor or poor households Amartya Sen has pointed out that the real cause of absolute poverty is the deprivation of viability, the absolute meaning of absolute poverty is the ability of poverty. Therefore, to improve the ability of the poor households is the key to achieve poverty alleviation, that is, "Delegated person to fish than to give them fish."Research about rural public investment in China "by experts shows that education investment has the most significant influence on rural economic growth and poverty alleviation, experts think that every additional 10,000 yuan of education investment can make nine people out of poverty.Because the development of education is not only conducive to improving the ability of poor groups, but also contributive to help all members of the family to form a correct outlook on the world, life and values, to enhance the internal power of poverty alleviation and the sustainability of poverty, to avoid the intergenerational transmission of poverty.

From the results of this survey, the poor out of poverty in 2016 mainly relied on non-agricultural income, but most of the poor households who are still unable to alleviate the poverty are owning low non-farm payrolls, so economic growth and initial distribution are difficult to increase its income. The reason for the low rate of non-farm income in poor households is mainly due to the lack of labor ability, besides the lack of labor force in five guarantees family. The reason for the gap between the poor households is that the educational level is different. The farmers have the opportunity to give up the education opportunities on the basis of the subjective and objective reasons. After the process of the same income source as the farmer who has not given up education, when the rate of educational return began to increase through the non-farm employment reaction to the income of the different results, the different results of income will bring reaction to the difference of educational starting points of next generation, so that poor households would step into trap of the non-farm employment rate and low income.

The level of education is the decisive factor in the labor force's possession of non-farm employment opportunities, and non-farm employment is also the decisive factor for poor families to get rid of poverty. The objective reason for giving up the opportunity for education is mainly the tension of employment.Employment is the driving force of educational development, it is also the primary goal of students to study hard.For rural students in poor areas, the expectation of changing the fate of the family by education is more intense.However, with the popularity of higher education in China, the difficulty of college students employment has gradually increased.If students can not be employed after graduation, the intrinsic motivation to study will be reduced, the investing enthusiasm for education of students and parent will decline.Therefore, the development of education and poverty in poverty-stricken areas has become a dilemma in poverty alleviation and development of employment.The main reason is that the development of education is not based on the economic and social development of poor areas and endogenous talent needs, but the artificial expansion driven by the external power. The structural contradiction between higher education and social demand leads to the dislocation of personnel training, "employment is difficult" and "recruitment is difficult" appear at the same time.Therefore, under the current employment situation, developing rural vocational and technical education to get rid of poverty has a direct practical significance.First of all, the development of rural vocational education is to cultivate modern new professional farmers, to ensure the successor of agricultural production needs;Second, the current market has large needs for talent with technical skills, through the differentiation of vocational skills training, the poor households can master a technology, which can increase their employment opportunities and wage levels; Finally, for young people who have left school in rural areas, vocational skills training is also an effective way to get out of poverty and improve social stability.Therefore, focusing on improving the education of the poor is the process of granting fisheries and work, it's also the result of poverty.

\section{B. "Relative poverty" in cultural context--Humbly interpret the content of people who are "relative poverty" and their lives, respect their ideal about a better life, help him to play the subjectivity.}

Absolute poverty, that is, whether the wealth of material can meet the needs of the poor needs of mankind, it described the problem of poverty which is not a purely natural state, but a kind of economic construction.If poverty is placed in a more open "cultural history" rather than the economic history, poverty will not a purely economic phenomenon any longer, but a complex social and cultural phenomenon.Marx said that "no matter how small the house is, if the surrounding houses are so small too, it is able to meet all the needs of the community on the housing.But once the house was built near the little house, the little house was shrinking into a poor hut......what's more, no matter how the size of the small house expand with the progress of civilization, as long as the nearby palace expand as the same or greater speed,residents in that smaller house will be more and more uncomfortable, more dissatisfied, more and more despised by others."Here we show that poverty is relative, social, and its essence, is a social existence, is the expression of human relations, because" our needs and enjoyment is generated by the community, so what we search for the needs and enjoyment is the scale of society, rather than to meet their items to measure.Because our needs and enjoyment owns a social character, they are relative."

Thus, in today's era of advocacy and choice, we will encounter poverty alleviation problems in intercultural contexts, such as the poverty alleviation of ethnic minorities in practical poverty alleviation work. At this time, because of the different cultural contexts, our values pursuit and way of life may be different from them, we can not blindly judge their life and world in our cultural context with our value system, give 
them affixed "ignorance", "unwisdom", "uncivilized" Label, and then use the way we think civilized to" help" them in our own kindness, the result of this basically brings misunderstanding, unwillingness and the loss of enthusiasm tp self-poverty alleviation, and poverty alleviation will be resulting in the loss of minority culture and so on.Therefore, we should advocate for the poor people to understand the content of the living world of "relatively poor" under different cultural backgrounds and different values, combine the knowledge of local knowledge and anti-poverty practices, and rebuild their world of life for the poor by providing political, economic and moral support and help, but the dominance of poverty is in the hands of the poor. themselves.

In particular, in poverty alleviation work, we need to adopt a path of anti-poverty in a fundamental participatory model, which refers to the creation of a free and equal consultation and discussion between the poor and workers,through the dialogue, communication and agreement to produce poverty alleviation "consensus", that is, poor workers humbly listen to the poor people's ideal of life, try to understand their expectations of a better life, to affirm the local experience and knowledge of poor groups, and then let them play a sense of ownership, rely on their own knowledge and experience to build their own living world.Among them, the responsibility of the workers are:1.Workers should build a bridge among power, the market and the poor, that is, to help them build an environment without stress and restraint, to create an open, free political space where the poor can feel cultural identity during the process of poverty alleviation, and then it can mobilize and inspire their autonomy and sense of responsibility, so that they get to characterize themselves and their cultural context, and then to rebuild their own life world, rather than rush into the lives of poor groups and interfere them in accordance with the modernization of the transformation program or stand as a savior.2. To some extent workers should combine their ideas and techniques with the experience and knowledge of the poor to raise the ideas and ways of expanding the reproduction needed by the poor, but to reproduce in a way that preserves their special group life.

\section{CONCLUSION}

The problem of poverty in the perspective of economics is "absolute poverty" in the context of modernity while in the cultural perspective is social "relative poverty".As Polanyi said:In fact, a social disaster is a cultural phenomenon rather than an economic phenomenon, "which reminds us of poverty alleviation work, we must put the problem of poverty in the community as a whole, explore poverty alleviation in multiangle ideas and ways."

In the past 30 years of poverty alleviation and development history, poverty alleviation work has made great achievements, and now at the final stage of poverty alleviation, it can be described as the final and the most hard period, the further works put forward, the more demand are, the higher demand for poverty alleviation are.Therefore, if we want to further promote poverty alleviation and development, we will need to focus on poor households first, and then understand the contents of their living world, respect their ideal about a better life, help develop a way to help them out of poverty, enlighten their ideas, impart modern knowledge and skills, and ensure that the poor are thinking of poverty and capacity growth, make the poverty alleviation become sustainable.

\section{ACKNOWLEDGMENT}

We would like to express our gratitude to all those who helped me during the writing of this thesis. This research paper was partially supported by Communication School, Yunnan University of Finance and Economics. Also as phased achievement, it is sponsored by National Social Science Research Project, Comparative Research on Investigation into Yunnan Dialect of Thai Mandarin (16BYY048). We thank our colleagues from Communication School who provided insight and expertise that greatly assisted the research.

We would also like to show our gratitude to the moderators for sharing their pearls of wisdom with us during the course of this research. And we also immensely grateful to reviewers for their comments on an earlier version of the manuscript. In addition, we would also thank peer reviewer for comments that greatly improved the manuscript.

Last, but not least, We recognize that this research would not have been possible without the financial assistance of the University of Finance and Economics, and other institutions, and express my gratitude to those agencies.

\section{REFERENCES}

[1] N. Len, "What Is To Be Done," People's Publishing House, 1971, p.37.

[2] Baidu Wikipedia.

[3] A.V. Banerjee, and D. Esther, "Poor Economics," DOP: 2013, p. 27.

[4] G.S. Fan, L.X. Zhang, and X.B. Zhang "The role of rural public investment in rural economic growth and anti poverty in China," Journal of South China Agricultural University, 2002.

[5] L.D. Zhang, "Intergenerational transfer of poverty in rural China and Empirical Study," China Population Resources and Environment, 2013.

[6] < Selections (Anthologies) of Marx and Engels $>$ vol. 1;Chinese People's Publishing House, 1972, p. 367.

[7] The concept of life-word comes from Edmund Husserl's phenomenology, which refers to the "pre-given world, which is always effective and is effective in advance as something that exists not for a certain purpose, subject matter, or in accordance with a general purpose".

[8] F. Zhang, "Poverty and anti poverty in the context of Modernity," Chinese People's Publishing House, 2009, pp. 241-242.

[9] P.Y. Karl, "The Great Transformation:The Political and Economic Origin of Our Time," Zhejiang People' s Publishing House, 2007, p. 134. 